\title{
Extraction followed by implant placement using Magnetic Mallet: a Case Report
}

\author{
Rajkumar $B^{1}$, Bhasin $A^{2}$, Shukla $P^{3}$, Gupta $V^{4}$, Bhatt $A^{5}$, Tekriwal $S^{6}$, KumarA ${ }^{7}$ \\ ${ }^{1}$ Dr. B. Rajkumar, HOD \& Professor, ${ }^{2}$ Dr. Anika Bhasin, Post Graduate Student, ${ }^{3}$ Dr. Preeti Shukla, Post Graduate \\ Student, ${ }^{4}$ Dr. Vishesh Gupta, Associate Professor, ${ }^{5}$ Dr. Akanksha Bhatt, Assistant Professor, ${ }^{6}$ Dr. Shweta Tekriwal, Post \\ Graduate, ${ }^{7}$ Dr. Aniket Kumar, Post Graduate. All affiliated with Department of Conservative Dentistry \& Endodontics \\ (ADD THIS), Babu Banarasi Das College of Dental Sciences, BBD University, Lucknow, India.
}

Address for Correspondence: Dr. Akanksha Bhatt, Assistant Professor. Department of Conservative Dentistry \& Endodontics, Babu Banarasi Das College of Dental Sciences, BBD University, Lucknow, India, Email: dr.a.bhatt@gmail.com

\begin{abstract}
Dental extractions sounds scary to the patients due to complications like dry socket, delayed healing,paresthesia, bleeding from site etc. This case reportintroduces a novel and innovative magneto-dynamical patented device Magnetic Malletused for extraction of the tooth followed by immediate implant placement. This method is least traumatic to patient and produces no post extraction complications with good quality bone healing.
\end{abstract}

Key Words: Dental Extraction, Dental Implants, Immediate Dental Implant loading.

\section{Introduction}

Conventional dental extraction procedures are associated with several postoperative complications like bleeding from site of extraction, dry socket, nerve paresthesia, delayed healing, periodontal pocket, and infection [1]. Magnetic mallet is a magneto dynamic patented medical devicehas application in sinus lift procedures, bone remodeling procedures, dental extractions, and insertion of implants after extraction. Dental extraction performed using this device can be done with minimal or without flap reflection to preserve the blood supply to facial bone plate thus reducing the risk of significant bone loss [2]. This presence of intact buccal bone plate and adequate soft tissues allows the placement of implant immediately.

The ergonomic hand-piece of the Magnetic Mallet can beoperated with only one hand and the impulses are applied with a control foot pedal, leaving the other hand free and allowing greater visibility of the operating field. The standard kit supplied with the Magnetic Mallet comprises a set of 10 tips including blades, bone

Manuscript received $10^{\text {th }}$ May 2016

Reviewed: $24^{\text {th }}$ May 2016

Author Corrected: $8^{\text {th }}$ June 2016

Accepted for Publication $20^{\text {th }}$ June 2016 expanders and drivers for inserting implants. With this kit it is possible to tackle all the various applications for which the instrument has been developed.

The impact of Magnetic Mallet ranges from 65 to 260 daN (deca Newton) in 120 microseconds when compared to conventional surgical mallet which ranges from 60 to $80 \mathrm{daN}$ in 300 microseconds, Hence the entire impact of magnetic mallet only affects the bone mass not the craniofacial mass thus giving least psychological trauma to patient [3]. The present case report makes a sincere attempt to introduce a new, innovative, unique and patented tool called as "Magnetic Mallet" manufactured by Meta Ergonomica Di Merlo Mario, Italyto perform tooth root extraction followed by immediate implant placement without trauma.

\section{Case Presentation}

A male patient aged 32 years reported to the OPD of department of Conservative Dentistry \& Endodontics, Babu Banarasi Das College of Dental Sciences, Lucknow, India with a chief complaint of broken tooth in upper front teeth. He gave history of trauma at his 
home in which his tooth got fractured and thereafter giving pain since 3 days. The physical build and gait of patient appeared normal. The medical history and extra oral findings were not significant. On Intra-oral Examination, it was observed that 22 toothwas fracturedandtender on vertical percussion. Past dental history statedthat patient had undergone root canal treatment in same tooth 2 years back. After a

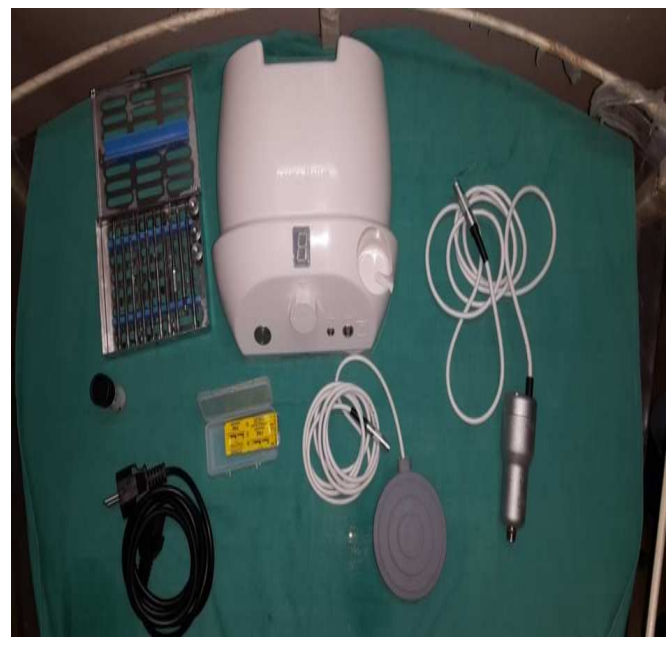

Figure1: Magnetic mallet Kit

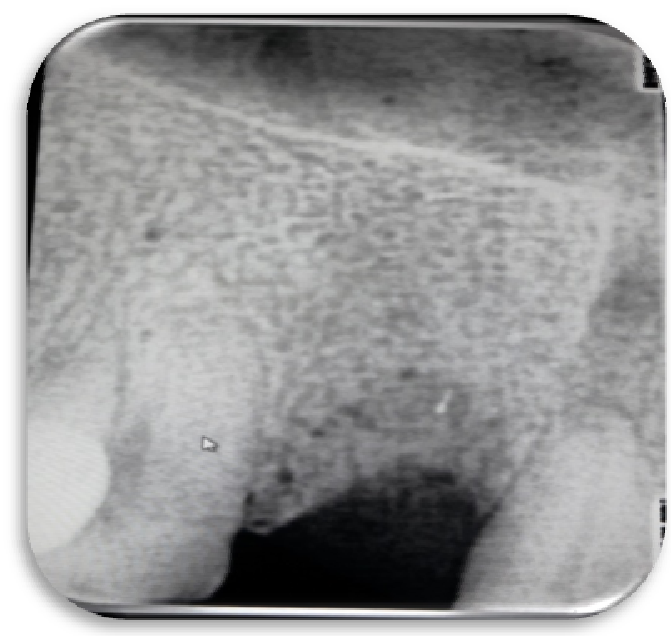

Figure- 3: Post extraction IOPA wrt 22 region. radiographic examination of that region it was revealed that the affected tooth hasaperiapical radiolucency with grade III mobility. A poor prognosis of 22 tooth clearly opted the tooth for extraction. The dental extraction was planned for same tooth followed by immediate implant placement aided with Magnetic Mallet (Figure1) after five days of antibiotic therapy along with antiinflammatory drugs.

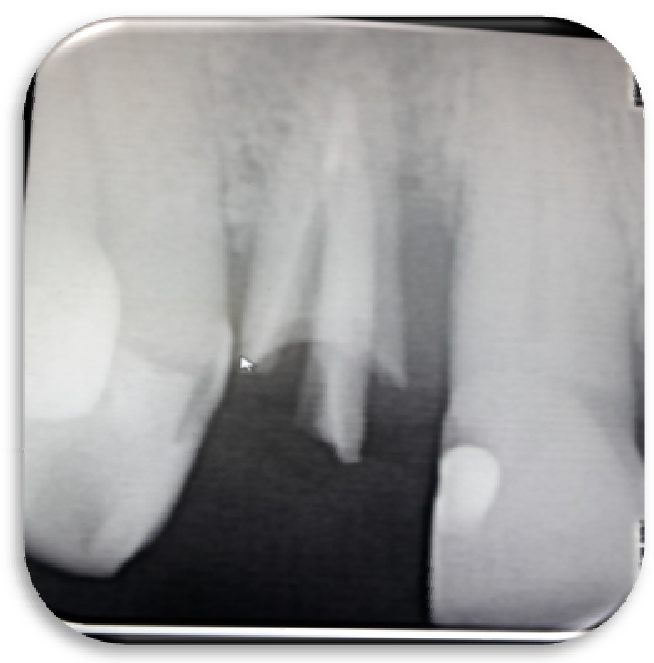

Figure-2: IOPA 22 revealing fractured tooth with incomplete root canal obturation.

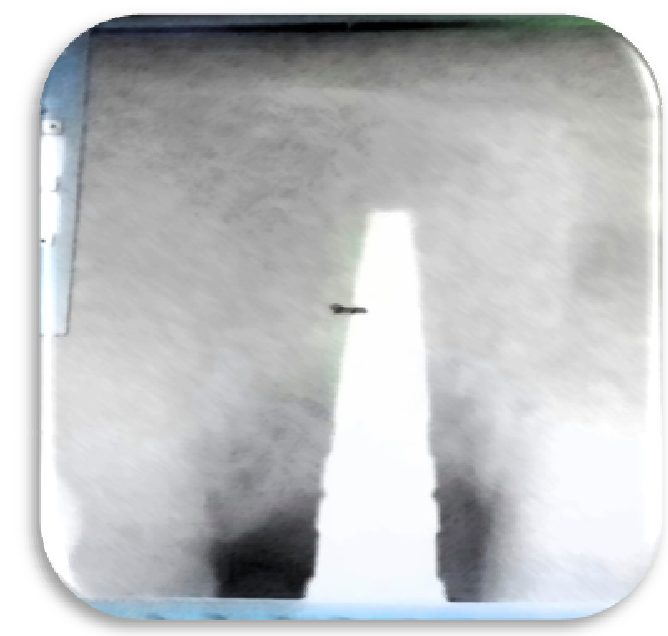

Figure-4: IOPA showing Magnetic Mallet Bone Osteotome just prior to Implant placement.

The local anesthesia 2\% (Lignocaine with adrenaline, 1:80,000, ICPA, Mumbai) was administered and tooth was luxated using EXTR 3 which is long spoon shaped instrument in the kit which fits well with the root anatomy of the tooth and was taken out by the same instrument. After the tooth was extracted a radiograph was taken so as to confirm in-toto removal of tooth (Figure 3). Osteotome no. 1 and no. 2 were used in sequence to gain $2 \mathrm{~mm}$ space beyond socket and a radiograph with osteotome was obtained before the implant placement (Figure 4). The implant of 3.75 diameter and 13 mm length was placed in the extraction socket followed by a radiograph (Figure5). All the extractors and osteotome used were attached to specializedergonomic handpiece which designed to provide a $30 \%$ higher force than the standard one, in order to facilitate the surgeon in penetrating maxilla bone having a greater density. It also delivered the clinician a ease of extraction [3]. 


\section{Discussion}

Atraumatic extraction methods are deemed to be important to minimize alveolar bone loss after tooth extraction and to facilitate subsequent implant restoration and optimal esthetic outcomes [4]. With the advent of such techniques, exodontia is no more a dreaded procedure in anxious patients. Newer systems and techniques for extraction of teeth have evolved in the recent few decades [5]. Magnectic Mallet being one of them offers advantages of faster recovery, no bone loss, less trauma during surgery, improving bone quality and prevents the so-called benign paroxysmal vertigo syndrome that is post-operative symptom of vertiginous nature. Moreover, the surgeon can operate with a greater visibility and control, preserving the bone and assuring the greatest possible comfort to the patient, both in complex implant surgeries and even in simple extractions [3]. It works at four different working intensities allowing the surgeon to modulate the force according to the type of operation needed and the receiving bone, proceeding with a greater safety margin and higher precision. With its numerous applications and advantages, MagneticMallet can be boon to the field of dentistry.

\section{Conclusion}

The Magnetic Mallet is an asset for dental and implant surgery for operator and patient in cases of maxillary sinus lift, vertical and horizontal bone compaction and expansion and more generally, in all cases where the blow of surgical hammer is normally used. Dental practitioners must make use of this system to provide high quality of treatment for their patients in a short duration of time causing no psychological trauma or fear.

Funding: Nil, Conflict of interest: None initiated. Permission from IRB: Yes

\section{References}

1. Motamedi MH. Concepts to consider during surgery to remove impacted third molars. Dent Today. 2007 Oct;26(10):136, 138-41; quiz 141, 129.

2.Kang J, Dym H, Stern A. Use of the power tomeperiotome to preserve alveolar bone during tooth extraction-A preliminary study. Oral Surg Oral Med Oral Pathol Oral RadiolEndod 2009;108:4.

3. Magnectic Mallet [Internet]. [Place: Italy] Sweden \& Martina. Available from :http://www.sweden-martina. com/7_magnetic-mallet_642.php.

4. Kumar MPS. Newer methods of Extraction of teeth. Int J Pharm Bio Sci2015; 6(3): 679 - 685.

5. White J, Holtzclaw D, Toscano N. Powertome assisted atraumatic tooth extraction. The Journal of Implant \& Advanced Clinical Dentistry 2009;1(6): $35-44$.

\section{How to cite this article?}

Rajkumar B, Bhasin A, Shukla P, Gupta V, Bhatt A, Tekriwal S, Kumar A. Extraction followed by implant placement using Magnetic Mallet: a Case Report. Int J Med Res Rev 2016;4 (6):1046-1048.doi: 10.17511/ijmrr.2016.i06.31. 